\title{
BMJ Open Insulin sensitivity assessed using urine $C$ peptide creatinine ratio (UCPCR) in pregnancy: cross-sectional analysis of an English multiethnic cohort
}

\author{
Ankica Markoska, Lilian C Mendoza, Rajalakshmi Valaiyapathi, Chloe Thorn, \\ Anne Dornhorst
}

To cite: Markoska A, Mendoza LC, Valaiyapathi R, et al. Insulin sensitivity assessed using urine $\mathrm{C}$ peptide creatinine ratio (UCPCR) in pregnancy: cross-sectional analysis of an English multiethnic cohort. BMJ Open 2018;8:e020029. doi:10.1136/ bmjopen-2017-020029

- Prepublication history for this paper is available online. To view these files, please visit the journal online (http://dx.doi org/10.1136/bmjopen-2017020029).

Received 13 0ctober 2017 Revised 23 January 2018 Accepted 6 March 2018
Check for updates

Department of Investigative Medicine, Faculty of Medicine, Hammersmith Hospital, Imperial College London, London, UK

Correspondence to

Anne Dornhorst;

a.dornhorst@imperial.ac.uk

\section{ABSTRACT}

Aims To assess urinary $C$ peptide creatinine ratio (UCPCR) used in a modified Matsuda equation to measure insulin sensitivity (IS) in pregnancy.

Research and design methods In this cross-sectional study, two IS measurements were calculated in 73 pregnant women at $\sim 28$ weeks of gestation by two separate methods using modified Matsuda equations. The first using the 0 and 120 min serum $C$ peptide concentration during a $75 \mathrm{~g}$ oral glucose tolerance test (OGTT) and the second using the 0 and 120 min UCPCR values. The calculated IS measurements from the two methodologies were evaluated using Person's test and linear regression analysis. The relationship between $\mathrm{IS}_{\text {OGT }}$ UCPCR and the fasting second void UCPCR and $120 \mathrm{~min}$ UCPCR was assessed using Pearson correlation and linear regression analysis after logarithmic transformation of the variables. Statistical analysis was performed using SPSS V.22.

Results The IS measured using serum C peptide (IS ${ }_{\text {pep }}$ ) in the modified Matsuda equation correlated with the IS measurement using serum UCPCR (IS $\left.{ }_{\text {OGTT-UCPCR }}\right)(\mathrm{r} 0.704$, $p<0.0001)$. A strong correlation was found between the $\mathrm{IS}_{\text {OGTT-UCPCR }}$ and the fasting UCPCR $(r-0.916, p<0.0001)$, displaying a hyperbolic relationship.

Conclusion The UCPCR provides a practical methodology to assess IS and $\beta$-cell function in pregnancy.

\section{INTRODUCTION}

In pregnancy, maternal normoglycaemia is dependent on insulin secretion increasing sufficiently to compensate for the physiological fall in insulin sensitivity (IS). In clinical practice, measuring insulin secretion is relatively straightforward using serum insulin, serum $\mathrm{C}$ peptide or the urinary $\mathrm{C}$ peptide. ${ }^{1-3}$ Urinary $\mathrm{C}$ peptide creatinine ratio (UCPCR), obtained using the fasting second-void urine sample, is strongly correlated with serum insulin, serum $\mathrm{C}$ peptide ${ }^{45}$ and 24 hours urinary $\mathrm{C}$ peptide, ${ }^{4}$ providing a practical and non-invasive method to assess insulin secretion. By contrast, measuring IS is much

\section{Strengths and limitations of this study}

- Urinary C peptide creatinine ratio (UCPCR) is a valid method to assess insulin secretion in and outside pregnancy. We are the first to report the use of UCPCR to assess insulin sensitivity in pregnancy using a modified Matsuda equation.

- A modified Matsuda equation using UCPCR provides a practical and non-invasive method to assess insulin sensitivity in pregnancy that could potentially be useful in epidemiological studies and clinical practice.

- We have observed a hyperbolic relationship between fasting UCPCR values and insulin sensitivity, suggesting that UCPCR could be used to estimate $\bowtie$-cell function.

- The study was conducted in pregnant women; therefore, the results cannot necessarily be extrapolated to a non-pregnant population.

more complex. The euglycaemic hyperinsulinaemic clamp, although the gold standard, is impractical for clinical use. The Matsuda Index $\left(\mathrm{IS}_{\mathrm{OGTT}}\right.$ ) provides a validated simpler alternative using serum glucose and insulin measurements during an oral glucose tolerance test (OGTT). ${ }^{6}$ In pregnancy, the Matsuda Index exhibits a stronger correlation with the euglycaemic hyperinsulinaemic clamp, than other IS models (ie, HOMAIR)..$^{7}$ A modified Matsuda Index that substitutes serum $\mathrm{C}$ peptide for insulin has been validated during pregnancy. ${ }^{8}$ Our previous work has shown that serum $\mathrm{C}$ peptide and UCPCR are strongly correlated during an OGTT in the latter half of pregnancy. ${ }^{9}$ Using data collected during this study, we evaluate whether maternal UCPCR obtained during an OGTT can replace serum $\mathrm{C}$ peptide in the previous validated modified Matsuda Index of Radaelli et al. ${ }^{8}$ We also evaluated the relationship between IS in the UCPCR-modified 
Matsuda equation and insulin secretion estimated by the second-void fasting UCPCR.

\section{Research design and methods}

The present study is a further analysis of a published prospective cross-sectional study undertaken in the maternity unit at Queen Charlotte's and Chelsea Hospital, London, UK. ${ }^{9}$ All women had given informed written consent. The original database was from 100 women prospectively recruited who agreed to provide an extra blood and urine sample during their routine diagnostic 28-week $75 \mathrm{~g}$ OGTT for gestational diabetes mellitus (GDM). Women were recruited over a 5-month period in 2016. All women were either 35 years old or above, expecting twins or had one or more risk factors for GDM according to the National Institute for Health and Care Excellence (NICE) guidelines. ${ }^{10}$ All women included had normal renal function. From the original dataset of 100 women, 27 were excluded from the current analysis, 2 with gestational age above 31 weeks, 1 with a renal transplant and 21 with urinary $\mathrm{C}$ peptide above the assay detection limit after automated 1:10 dilution. A further three women were not included in the final analysis due to missing $120 \mathrm{~min}$ UCPCR data.

All women attended the 2-hour $75 \mathrm{~g}$ OGTT fasted and had passed their overnight first void urine. Fasting and 2-hour blood samples were taken for plasma glucose and serum $\mathrm{C}$ peptide. Urine samples were collected at the beginning (second void urine) and end of the OGTT.

The blood glucose was collected in fluoride oxalate tubes and processed in the routine hospital laboratory using the hexokinase/G-6-phosphate dehydrogenase spectrophotometric method, with an imprecision of $\leq 5 \%$ of the total coefficient of variation (CV), performed on Abbott Architect c System. The C peptide blood sample was collected on ice, before centrifugation and the plasma stored in $1 \mathrm{~mL}$ cryotubes at $-80^{\circ} \mathrm{C}$.

The urinary $\mathrm{C}$ peptide was collected and stored in boric acid tubes before being aliquoted into $1 \mathrm{~mL}$ cryotubes and stored at $-80^{\circ} \mathrm{C}$. Urinary creatinine was assayed using the kinetic alkaline picrate method with a total $\mathrm{CV}$ of $\leq 6 \%$ (Abbott Architect ci16200 System) to obtain the UCPCR.

Urinary and serum $\mathrm{C}$ peptide were measured on an Abbott Diagnostics Architect platform (Abbott Laboratories, Abbott Park, Illinois, USA), using a two-step chemiluminescent microparticle immunoassay, with measurement ranges between 3.33 and $10000 \mathrm{pmol} / \mathrm{L}$.

\section{Box 1 Serum $\mathbf{C}$ peptide replaces serum insulin in the} original Matsuda equation and $\mathbf{5 0 0 0 0 0}$ is used as the numerator

$I_{\text {oGTTC-pep }}=500000 / \sqrt{ }\{[$ FPGXFsC-pep $] \times$ [mean glucose $\times$ mean sC-pep during the $0 \mathrm{GTT}]\}$

FPG, fasting plasma glucose (mg/dL); FsC-pep, fasting serum C peptide (pmol/L); IS, insulin sensitivity; OGTT, oral glucose tolerance test; sC-pep, serum C peptide (pmol/L).
Box 2 Urinary C peptide creatinine ratio (UCPCR) values at fasting and the mean UCPCR between 0 and $120 \mathrm{~min}$ replace the fasting and mean insulin values in the original Matsuda equation. $\mathbf{5 0 0 0 0 0}$ was also used here as the numerator

$I_{\mathrm{OGTT}_{\text {UCPCR }}}=500000 / \sqrt{ }\{[\mathrm{FPG} \times \mathrm{FUCPCR}] \times[$ mean glucose $\times$ mean UCPCR during the $0 \mathrm{GTT}]\}$

FPG, fasting plasma glucose; FUCPCR, fasting UCPCR (pmol/mmol); IS, insulin sensitivity; OGTT, oral glucose tolerance test.

The Architect $\mathrm{C}$ peptide assay was designed to have a precision of $\leq 10 \%$ total CV. Automated dilution of 1:10 was performed in urine samples exceeding the upper limit of assay detection.

Calculation of IS was made using two different modified Matsuda equations. The first equation used serum $\mathrm{C}$ peptide, as previously validated in pregnancy by Radaelli $e t a l l^{8}$ (box 1). In the second equation, IS was calculated replacing serum $C$ peptide for UCPCR values (box 2).

Numeric data are presented as mean and SD, or median and IQR. Categorical data are shown as percentages. Data not normally distributed were

Table 1 Participants characteristics and oral glucose tolerance test (OGTT) results

\begin{tabular}{|c|c|c|}
\hline Characteristics & $\begin{array}{l}\%, \text { mean }( \pm S D) \text { or } \\
\text { median }(I Q R)\end{array}$ & $\mathbf{n}$ \\
\hline Maternal age (years) & $34.1( \pm 4.7)$ & 76 \\
\hline BMI $\left(\mathrm{kg} / \mathrm{m}^{2}\right)$ & $23.8(5.8)$ & 76 \\
\hline Ethnicity & & 76 \\
\hline Caucasian & $51.3 \%$ & \\
\hline South Asian & $17.1 \%$ & \\
\hline South East Asian & $9.2 \%$ & \\
\hline Middle Eastern & $13.2 \%$ & \\
\hline Black (African/Caribbean) & $3.9 \%$ & \\
\hline Other & $5.3 \%$ & \\
\hline Parity & & 76 \\
\hline Nulliparous & $56.6 \%$ & \\
\hline Multiparous & $43.4 \%$ & \\
\hline Singleton pregnancy (yes) & $94.6 \%$ & 76 \\
\hline Gestational age (weeks) & $28.0(0.28)$ & 76 \\
\hline \multicolumn{3}{|l|}{ OGTT results } \\
\hline Fasting glucose (mmol/L) & $4.4(0.5)$ & 76 \\
\hline Fasting C peptide (pmol/L) & $0.48(0.29)$ & 75 \\
\hline Fasting UCPCR (pmol/mmol) & $2.93(2.02)$ & 75 \\
\hline 2-Hour glucose (mmol/L) & $5.4(1.9)$ & 76 \\
\hline 2-Hour C peptide (pmol/L) & $2.12(1.14)$ & 75 \\
\hline 2-Hour UCPCR (pmol/mmol) & $12.06(11.4)$ & 73 \\
\hline GDM (yes) & $5.3 \%$ & 76 \\
\hline
\end{tabular}

BMI, body mass index; GDM, gestational diabetes mellitus; UCPCR, urinary $\mathrm{C}$ peptide creatinine ratio. 
A

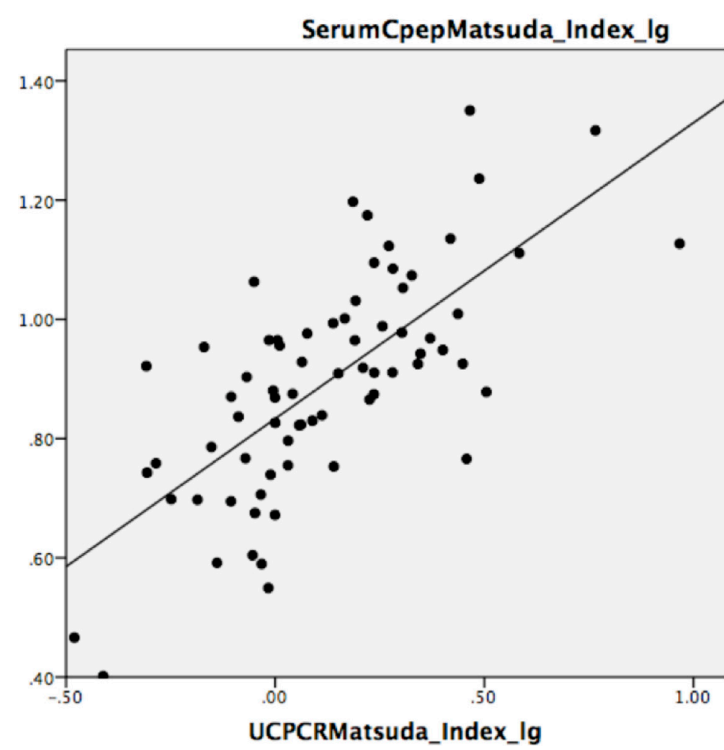

B

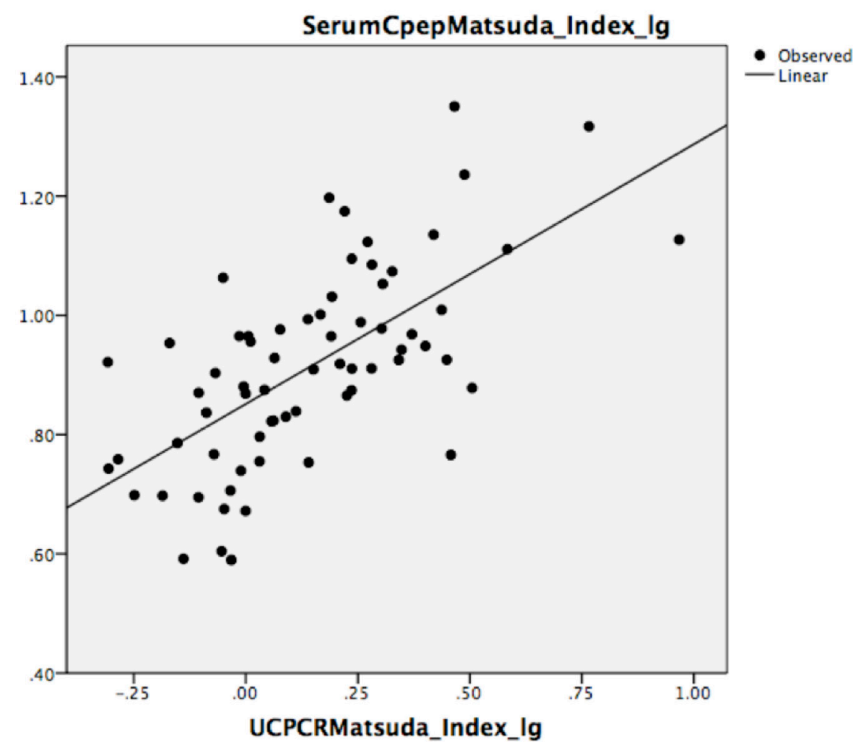

Figure 1 Linear regression models for $I_{\text {OGTC-pep }}$ and IS $S_{O G T-U C P C R}:(A)$ in the full cohort: $Y=0.833+0.496 X, r=0.704, p<0.001$ and (B) excluding women with gestational diabetes mellitus (GDM): $Y=0.851+0.436 \mathrm{X}, \mathrm{r}=0.654, \mathrm{p}<0.001$. IS, insulin sensitivity; OGTT, oral glucose tolerance test; UCPCR, urinary $C$ peptide creatinine ratio.

$\log$ transformed for analysis. We evaluated the correlation between two modified Matsuda equations (boxes 1 and 2) using Pearson correlations and linear regression analysis. A sensitivity analysis was performed excluding the four women with GDM.

The relationship between insulin secretion and IS displays a hyperbolic function. ${ }^{11} 12$ To verify if the OGTTbased measures of insulin secretion and IS in this study displayed a hyperbolic relationship, the following regression analysis was performed: $\log$ (secretion measure $)=-$ constant $+\beta \times \log$ (sensitivity measure). The criteria for a hyperbolic relationship were then applied: (1) $\beta$ is approximately equal to -1 and (2) the $95 \%$ CI of $\beta$ excludes $0 .{ }^{12} 13$

Statistical analysis was performed using SPSS V.22. A $\mathrm{p}$ value of $<0.05$ was considered statistically significant.
A

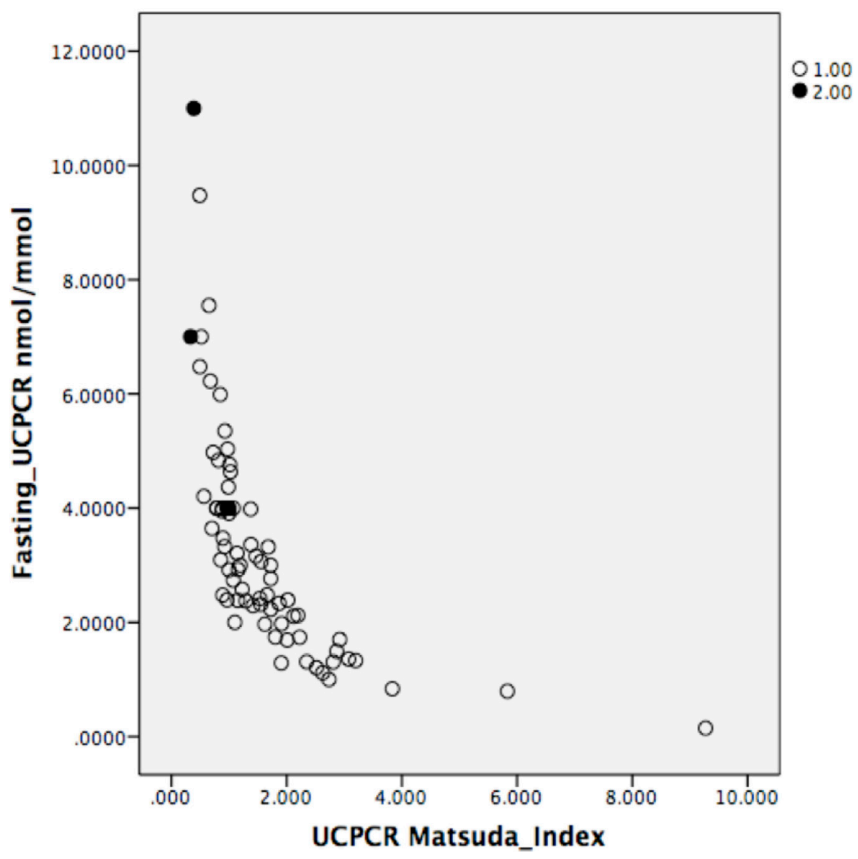

B

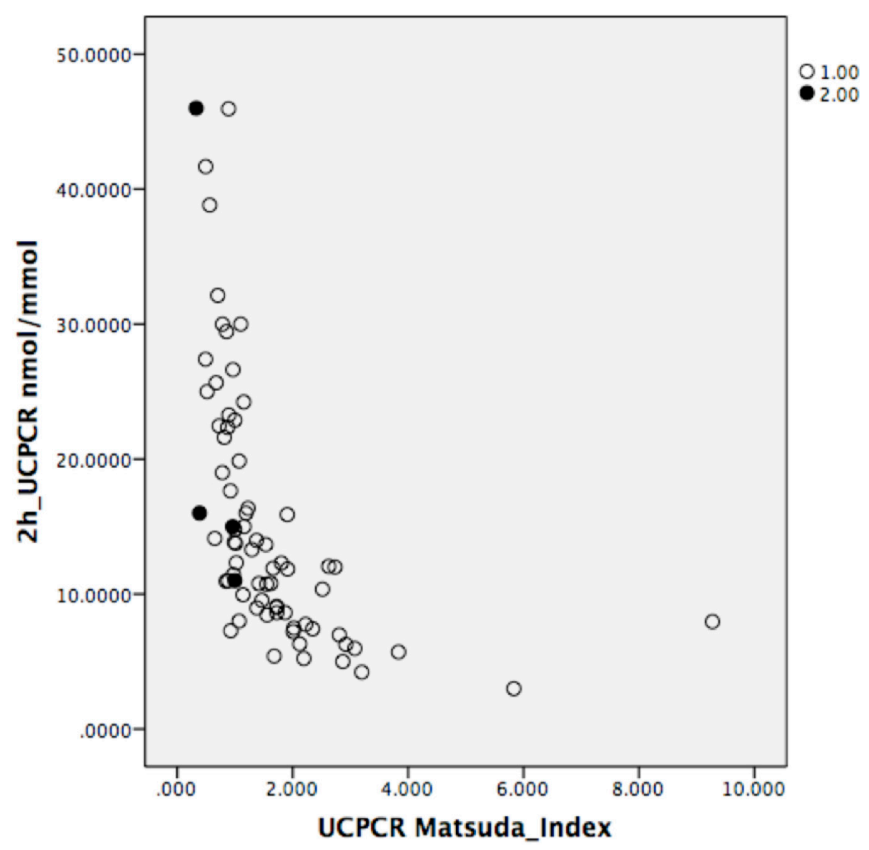

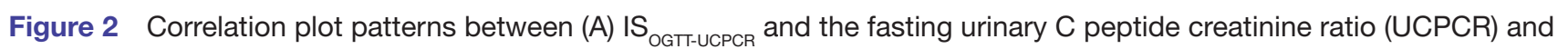
(B) IS $_{\text {OGTT-UCPCR }}$ and the 2-hour UCPCR. Women with gestational diabetes mellitus (GDM) are highlighted in black. IS, insulin sensitivity; OGTT, oral glucose tolerance test. 


\section{RESULTS}

The 76 participant characteristics and their OGTT results are summarised in table 1 .

The median estimates for IS $_{\text {OGTT-pep }}$ and IS $_{\text {OGTT-UCPCR }}$ were $8.1(2.5-22.4)$ and $1.2(0.3-9.3)$, respectively.

The two IS indexes calculated (IS $\mathrm{IGGTC \text {pep }}_{\text {a }}$ and $\mathrm{IS}_{\text {OGTT- }}$ UCPCR $)$ were significantly correlated $(r=0.704, p<0.0001)$ The linear regression model is summarised in figure 1A.

The association between IS $_{\text {OGTTc-pep }}$ and IS $_{\text {OGTT-UCPCR }}$ remained significant after excluding the four women with GDM in the sensitivity analysis $(r=0.654, \mathrm{p}<0.0001)$. The linear regression model is summarised in figure $1 \mathrm{~B}$.

The IS $_{\text {OGTT-UCPCR }}$ showed a strong correlation with both the fasting and the $120 \mathrm{~min}$ UCPCR $(\mathrm{r}=-0.916, \mathrm{p}<0.0001)$ $(\mathrm{r}=-0.777, \mathrm{p}<0.0001)$, respectively. A hyperbolic plot pattern was observed between $\mathrm{IS}_{\text {OGTT-UCPCR }}$ and both, fasting and $120 \mathrm{~min}$ UCPCR (figure 2A, B). The four women who had GDM by NICE criteria fell on the lefthand side of this hyperbola in both graphs.

A hyperbolic relationship was displayed between IS ${ }_{\text {OGTT- }}$ UCPCR and the fasting UCPCR ( $\beta-1.002,95 \%$ CI -1.105 to $-0.898, \mathrm{p}<0.001$ ) (figure $3 \mathrm{~A}$ ).

In the sensitivity analysis, excluding the four women with GDM, both of the hyperbolic criteria were consistent with the existence of a hyperbolic relationship between these two measures $(\beta-1.019,95 \% \mathrm{CI}-1.132$ to -0.907 , $\mathrm{p}<0.001$ ) (figure $3 \mathrm{~B}$ ).

However, the relationship between IS ${ }_{\text {OGTT-UCPCR }}$ and the 120 min UCPCR did not fulfil the hyperbolic function criteria $(\beta-0.767)$.

\section{DISCUSSION}

In this study, IS in pregnant women was calculated using two different modifications to the original Matsuda equations

A

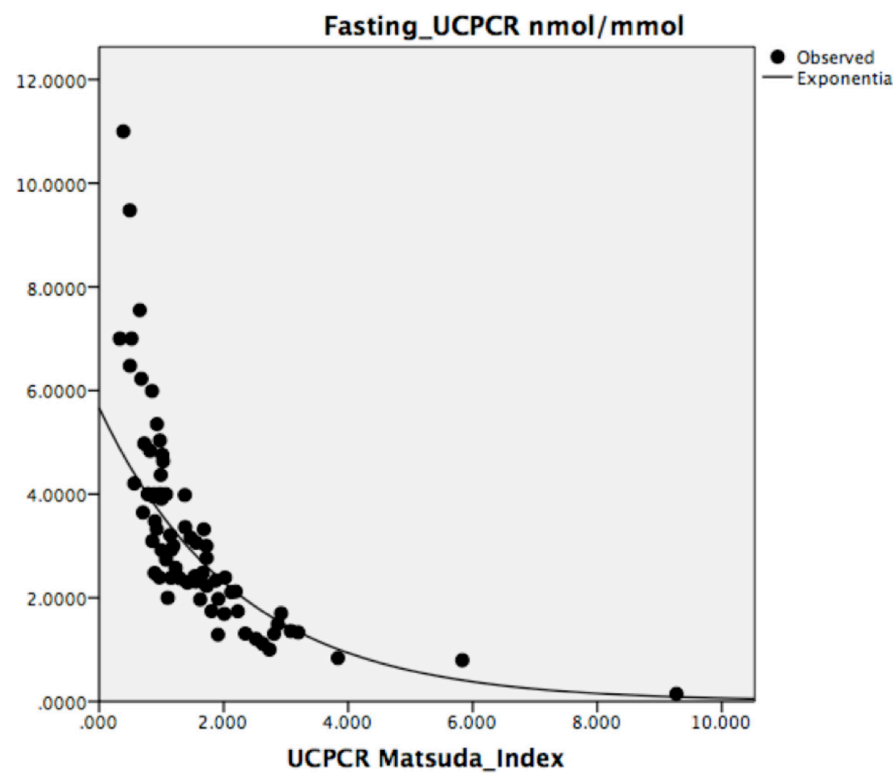

that replaced serum insulin in the original equation for either serum C peptide or UCPCR. The indexes calculated by both methods were well correlated. In pregnancy, the Matsuda equation using serum $\mathrm{C}$ peptide has been validated against the original method described by Matsuda using serum insulin. ${ }^{8}$ Furthermore, in pregnancy, it has shown a better correlation with IS derived using the euglycaemic hyperinsulinaemic clamp than Homeostasis assessment model - insulin resistance (HOMA-IR). ${ }^{7}$ This may be as HOMA-IR is highly dependent on basal hepatic insulin resistance $^{6}$ rather than total glucose disposal which will include maternal and fetal glucose uptake.

The use of the UCPCR provides a more convenient and practical method of assessing insulin secretion, as it is stable at room temperature for 3 days. ${ }^{4}$ UCPCR has proven to be a robust tool to assess insulin secretion, having a good correlation with both circulating insulin concentrations and serum $\mathrm{C}$ peptide. ${ }^{5}$ The fasting second-void urine UCPCR reflects an integrated measurement over time that has shown to be strongly correlated with 24 hours urinary C peptide measurements. ${ }^{4}$ Our current results show that UCPCR provides an estimate of insulin secretion and it can, in a modified Matsuda equation, be used to assess IS.

A hyperbolic relationship was observed between IS $_{\text {OGTT-UCPCR }}$ and the fasting UCPCR, in our study. This mirrors the hyperbolic relationship that defines the Disposition Index (DI), the product of insulin secretion and IS, ${ }^{11}$ which has been proposed as a measure of $\beta$-cell compensatory capacity, in both pregnant ${ }^{14}$ and non-pregnant subjects. ${ }^{12}$

The utility of the DI as a measure of $\beta$-cell function was defined by the hyperbolic relationship between insulin secretion and IS derived from the intravenous glucose tolerance test. ${ }^{15}$ More recently, this relationship has been

\section{B}

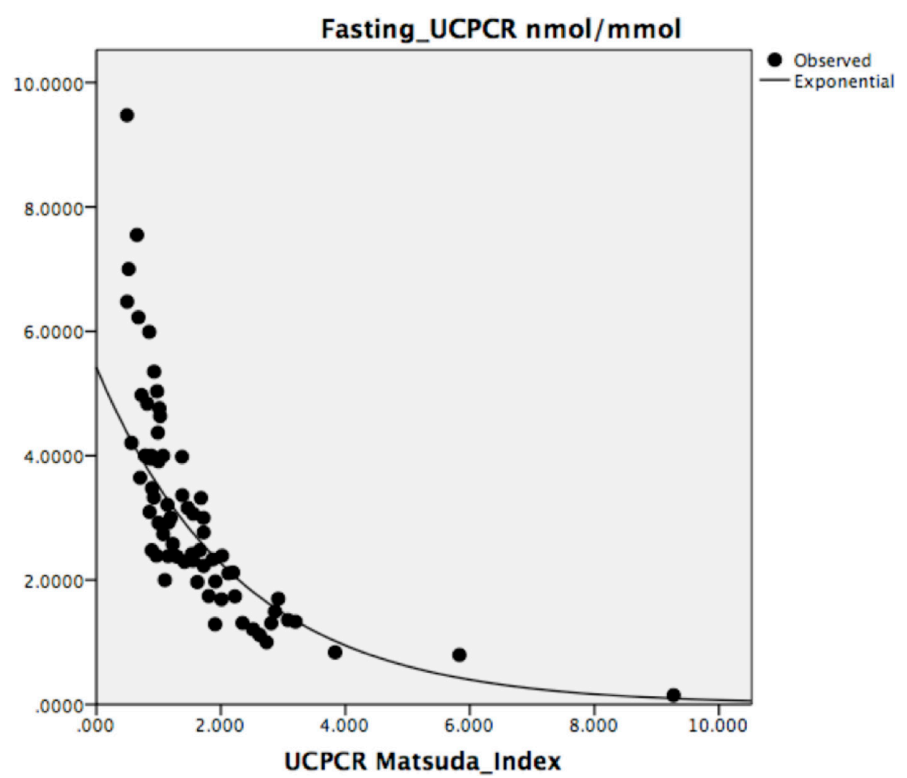

Figure 3 Hyperbolic relationship displayed between $I_{\text {OGTT-UCPCR }}$ and the fasting urinary C peptide creatinine ratio (UCPCR): (A) in the full study cohort and (B) excluding the four women with GDM. IS, insulin sensitivity; OGTT, oral glucose tolerance test. 
observed using parameters derived from the OGTT. ${ }^{13}$ Our work suggests that UCPCR substituted into the Matsuda equation can also offer information regarding $\beta$-cell function during pregnancy.

It has been established that women entering pregnancy with decreased IS are more at risk of developing GDM. ${ }^{16}$ UCPCR, as an easy and non-invasive clinical method to assess IS, could potentially help identify women most at risk of developing GDM in early pregnancy, allowing targeted lifestyle modification to lessen the risk of GDM. There is increasing evidence that lifestyle and therapeutic intervention after 18 weeks of pregnancy in at-risk women has little effect on preventing both GDM and fetal macrosomia. ${ }^{17-19}$ By contrast, earlier intervention with diet and physical activity may have a beneficial role. ${ }^{20}$

A practical and accurate method to estimate IS in pregnancy could also be informative in better understanding the epigenetic impact of maternal obesity and glucose homeostasis on the fetus. ${ }^{2122}$

A limitation of this study is that all women included had one or more risk factors for GDM. The study was conducted in pregnant women and therefore the results cannot necessarily be extrapolated to the non-pregnant population. Further studies on a larger scale are needed to corroborate these findings and confirm whether UCPCR could potentially be used to assess an individual's risk for developing GDM.

In summary, we have shown that the UCPCR-derived Matsuda Index in pregnancy is correlated with the serum C peptide-derived index, as validated by Radaelli et al. The relationship between IS estimated by the UCPCR-derived Matsuda equation and the fasting and post-OGTT UCPCR showed a hyperbolic relationship that suggests that this measurement could be useful to assess $\beta$-cell compensatory capacity in pregnancy.

Acknowledgements We would like to thank Ludwig Lupak for his expert support in conducting the biochemical analysis.

Contributors AM designed and conducted the study, analysed the data, interpreted the results and wrote the manuscript. LCM contributed to the data analysis, interpreting the results and writing of the manuscript. RV and CT contributed to the conduct of the study and data analysis. $A D$ is the guarantor of this work and, as such, had full access to all the data in the study and takes responsibility for the integrity of the data and the accuracy of the data analysis.

Funding This study was funded by Imperial College of London.

Competing interests None declared.

Patient consent Obtained.

Ethics approval Imperial College Healthcare NHS Trust Tissue Bank and and the Research Ethics Committee Wales: 12/WA/0196.

Provenance and peer review Not commissioned; externally peer reviewed.

Data sharing statement Data supporting this study are stored by the corresponding author at Imperial College London and will be available on request.

Open Access This is an Open Access article distributed in accordance with the Creative Commons Attribution Non Commercial (CC BY-NC 4.0) license, which permits others to distribute, remix, adapt, build upon this work non-commercially, and license their derivative works on different terms, provided the original work is properly cited and the use is non-commercial. See: http://creativecommons.org/ licenses/by-nc/4.0/ (c) Article author(s) (or their employer(s) unless otherwise stated in the text of the article) 2018. All rights reserved. No commercial use is permitted unless otherwise expressly granted.

\section{REFERENCES}

1. DeFronzo RA, Tobin JD, Andres R. Glucose clamp technique: a method for quantifying insulin secretion and resistance. Am J Physio 1979;237:E214-23.

2. Van Cauter E, Mestrez F, Sturis J, et al. Estimation of insulin secretion rates from C-peptide levels. Comparison of individual and standard kinetic parameters for C-peptide clearance. Diabetes 1992;41:368-77.

3. Hoogwerf BJ, Barbosa JJ, Bantle JP, et al. Urinary C-peptide as a measure of beta-cell function after a mixed meal in healthy subjects: comparison of four-hour urine C-peptide with serum insulin and plasma C-peptide. Diabetes Care 1983;6:488-92.

4. McDonald TJ, Knight BA, Shields BM, et al. Stability and reproducibility of a single-sample urinary $\mathrm{C}$-peptide/creatinine ratio and its correlation with 24-h urinary C-peptide. Clin Chem 2009;55:2035-9.

5. Oram RA, Rawlingson A, Shields BM, et al. Urine C-peptide creatinine ratio can be used to assess insulin resistance and insulin production in people without diabetes: an observational study. BMJ Open 2013;3:e003193.

6. Matsuda M, DeFronzo RA. Insulin sensitivity indices obtained from oral glucose tolerance testing: comparison with the euglycemic insulin clamp. Diabetes Care 1999;22:1462-70.

7. Kirwan JP, Huston-Presley L, Kalhan SC, et al. Clinically useful estimates of insulin sensitivity during pregnancy: validation studies in women with normal glucose tolerance and gestational diabetes mellitus. Diabetes Care 2001;24:1602-7.

8. Radaelli T, Farrell KA, Huston-Presley L, et al. Estimates of insulin sensitivity using glucose and C-Peptide from the hyperglycemia and adverse pregnancy outcome glucose tolerance test. Diabetes Care 2010;33:490-4.

9. Markoska A, Valaiyapathi R, Thorn C, et al. Urinary C peptide creatinine ratio in pregnant women with normal glucose tolerance and type 1 diabetes: evidence for insulin secretion. BMJ Open Diabetes Res Care 2017;5:e000313.

10. NICE. Diabetes in pregnancy: management of diabetes and its complications from preconception to the postnatal period: NICE Guidel NG3, 2015:2007-9.

11. Bergman RN, Phillips LS, Cobelli C. Physiologic evaluation of factors controlling glucose tolerance in man: measurement of insulin sensitivity and beta-cell glucose sensitivity from the response to intravenous glucose. J Clin Invest 1981;68:1456-67.

12. Kahn SE, Prigeon RL, McCulloch DK, et al. Quantification of the relationship between insulin sensitivity and beta-cell function in human subjects. Evidence for a hyperbolic function. Diabetes 1993;42:1663-72.

13. Retnakaran R, Shen S, Hanley AJ, et al. Hyperbolic relationship between insulin secretion and sensitivity on oral glucose tolerance test. Obesity 2008;16:1901-7.

14. Buchanan TA. Pancreatic B-cell defects in gestational diabetes: implications for the pathogenesis and prevention of type 2 diabetes. $J$ Clin Endocrinol Metab 2001;86:989-93.

15. Bergman RN, Ader M, Huecking K, et al. Accurate assessment of beta-cell function: the hyperbolic correction. Diabetes 2002;51(Suppl 1):S212-S220.

16. Xiang $\mathrm{AH}$, Kjos SL, Takayanagi M, et al. Detailed physiological characterization of the development of type 2 diabetes in Hispanic women with prior gestational diabetes mellitus. Diabetes 2010;59:2625-30.

17. Briley AL, Barr S, Badger S, et al. A complex intervention to improve pregnancy outcome in obese women; the UPBEAT randomised controlled trial. BMC Pregnancy Childbirth 2014;14:74.

18. Syngelaki A, Nicolaides KH, Balani J, et al. Metformin versus Placebo in Obese Pregnant Women without Diabetes Mellitus. N Engl J Med 2016;374:434-43.

19. Simmons D, Devlieger R, van Assche A, et al. Effect of physical activity and/or healthy eating on GDM Risk: The DALI lifestyle study. $J$ Clin Endocrinol Metab 2017;102:903-13.

20. Wang S, Ma JM, Yang HX. Lifestyle intervention for gestational diabetes mellitus prevention: A cluster-randomized controlled study. Chronic Dis Transl Med 2015;1:169-74.

21. Bouchard L, Thibault S, Guay SP, et al. Leptin gene epigenetic adaptation to impaired glucose metabolism during pregnancy. Diabetes Care 2010;33:2436-41.

22. St-Pierre J, Hivert MF, Perron P, et al. IGF2 DNA methylation is a modulator of newborn's fetal growth and development. Epigenetics 2012;7:1125-32. 